\title{
Patient involvement in lung foundation research: A seven year longitudinal case study
}

\author{
G. J. Teunissen ${ }^{1,2^{*}}$, M. A. Visse ${ }^{2}$, D. Laan ${ }^{1}$, W. I. de Boer ${ }^{1}$, M. Rutgers ${ }^{1}$, \\ T. A. Abma ${ }^{2}$ \\ ${ }^{1}$ Lung Foundation Netherlands, Amersfoort, The Netherlands; \\ *Corresponding author: truusteunissen39@gmail.com \\ ${ }^{2}$ Department of Medical Humanities, VU University Medical Centre, EMGO+, Amsterdam, The Netherlands
}

Received 13 December 2012; revised 12 January 2013; accepted 20 January 2013

\section{ABSTRACT}

Patient involvement in health research is getting more accepted over the years. Until recently scientists and medical professionals were the sole assessors of quality and relevance of research proposals. In the Netherlands, as in other European and North American countries, emancipatory, political and democratic developments stimulated the emergence of patient involvement as a new "voice" in the appraisal of research. A time-series cross sectional longitudinal case study was used to describe and analyse a seven year period since the introduction of the patients' perspective in the Longfonds research cycle. Longfonds, the Lung Foundation in the Netherlands (LFN) was formerly called "Astma Fonds". The study was conducted using an actors-interaction model against the background of the dynamics in society. The introduction of patient involvement resulted in a paradigm shift. The scientific and societal relevance of research proposals are now being reviewed by all parties in a more effective and efficient way. Patients, now involved in the review procedure of research funding, are trained and equipped with an appraisal tool for societal relevance from a patients perspective. Scientific relevance and societal relevance are evaluated separately and balanced in the research funding application approval process. Societal relevance is being evaluated by a patient advocates group. The results show how a government initiative and an approach by a patient organisation have led to more patient involvement in lung research. It requires "believers" both to initiate and continue the work and to promote the lessons learned inside and outside the patient organisation. As this de- pends on devoted individuals, the continuity of patient involvement remains vulnerable. This seven year study offers valuable insight in patient involvement against the background of the changeing health discourse.

Keywords: Appraisal; Lung Patient; Participation; Patient Involvement; Lay Expertise; Medical

Research; Quality of Life; Commitment

\section{INTRODUCTION}

Scientific medical research has been the exclusive domain of (bio-or para) medical scientists doing scientific research for a long time. Research is often initiated by researchers from a scientific perspective (bottom-up) or by institutes, funding organizations or patient organisations funding research (top-down). Theme choice, appraisal and prioritizing are usually done only from the scientific perspective. In Western societies, a general trend towards more emancipation and exerting democratic rights by citizens with disabilities is being observed [1]. Literature search shows that patient involvement at a health fund has thus far not been subject of a long term case study. Several years ago LFN started to look at possibilities for "patient involvement" in theme choice and appraisal in LFN research. Currently, the LFN scientific advisory board (WAC) not only consists of scientists but also has three permanent lung patient members with experiental knowledge [2]. This article reports a study on the introduction and evaluation of patient involvement in the LFN cycle of research funding. The study is carried out against the background of a model of actors and interactions and looks at five transition phases over a seven year period. These phases lead to five comparable situation descriptions over time from evidence gathered. This result is analysed and discussed to assess lessons learned. 


\section{METHOD}

\subsection{Design of the Study}

An in-depth study of the development, effects and background of patient involvement in the research cycle at LFN, can best be carried out with the case study method, following the basic principles and methodological rigor as layed out by Yin et al. [3]. Field-work for data gathering requires a "blueprint" theory and suitable data collection instruments [4]. This case is the "carrier" of the subject phenomenon "patient involvement" at LFN [5].

\subsection{Selection of Type and Instruments}

Eisenhardt (1989) [6] presents a general 7 steps case study approach and underlines the importance of methodological rigor. For this study a variant is used, adapted and re-grouped into 4 main steps: design, conduct, analyse and, finally, formulation of the evidence outcome.

Kohn (1997) [7] focuses on case study analysis and links it to the need for a logic model covering process/context system, identification of actors, their roles and behaviour, expected changes, actor strategy and function in the system, driving forces, interactions among actors.

The 7 year investigation period necessitates a longitudinal approach rather than a latitudinal one. The main challenge is the thematic analysis over time. Such studies are referred to as "time-series cross sectional" (TSCS). Several discussion points must be noted here, e.g. whether the perspective (or ability) of the researcher is changing $[8,9]$.

\subsection{Data Gathering}

Based on the above considerations, the LFN case study design comprises 5 cross-sections over time. The inductive analysis technique [10] was used to constitute 7 themes. Each of these situation descriptions addresses the same themes. Collection of evidence took place via:

- Documents (minutes of meeting; interviews; policy reports), Several documents used in this case study were confidential. They are not listed in the references.

- "Open" interviews, (questions like: how, why) In total 10 open interviews were held by the first author with patient representatives participating inside and outside the LFN organisation in the period 2009-2012. Interviews typically lasted $45 \mathrm{~min}$ and a topic list was used to ensure theme completeness. A further 4 open interviews with research professionals and external research scientists with a role in the LFN research funding process were held. New interview questions were raised until the themes in the list were all discussed. After each of these 14 interviews a member check was performed.

- Direct observation and observation by participants (in focusgroups). A scientific advisory board meeting with 14 (out of 23) members was held in 2011 while being monitored via direct observation. The board members were research professionals, medical professionals, care providing professionals and two-high educated-patient representatives. The observation by 2 researchers was set up to explore their behaviour in the discussions: topics, tone, respect, formal or informal, interruptions and discussion lines. A series of 4 focusgroups were held in 2009 (20 participants), 2010 (18), 2011 (17) and 2012 (18) to gather experiences, issues and concerns emerging from the patient involvement activities, based on a topic list. These meetings typically lasted 2 hours and were held at a neutral location. Written summaries were made and member checked with all participants. The participants were highly educated people between 18 and 76 years of age, men and women. All participants have a chronic lung disease, are patient representatives and participate in the LFN research proposals societal relevance appraisal process. Further direct observation by the first author as a policy advisor during 3 appraisal cycles in 2010, 2011 and 2012 added insight into the practical problems of funding proposal appraisal. Participants in interviews and focusgroups were treated according to the declaration of Helsinki [11].

\subsection{Data Analysis}

Interview transcripts and notes taken during focusgroups were used to make descriptions at 5 transition phases over time. These time-crossectional situation descriptions have directed content using a 7 themes template. All gathered data were then tabulated in summarized form in a simple transcript matrix with rows according to Table 1 and columns according to Table 2 . The notes made during the direct observations were used for reference in this process. Then 7 histories by theme were composed from this matrix.

\subsection{Quality Criteria}

Based on quality considerations like validity and reliability [12] general criticism on the case study method points at sensitivity for ethical problems, mixed interests of the researchers, sensitivity to pre-disposition and uncontrolled change of direction during the study. These dangers were avoided by the above choice of methods, use of well proven techniques and accurate description of the analysis. The first author conducted the research over the entire period. 


\section{CASE}

The case study requires a model, a "blue print" describing the LFN patient involvement actors and interacttions. The actors are the different stakeholders (see Figure 1). The model is based on the current LFN research funding process design. The definition of patient involvement as presently used by the Dutch Government determines how we look at patients representatives and their role [13].

\subsection{Definition of Patient Involvement}

About half the people with a chronic disease have some sort of physical disability degrading their self-sufficiency and participation in society. Personal factors (e.g. knowledge and skills) and environmental factors (e.g. access to care) determine the level of problems they experience with this [14]. Patients try to arrange their lives around the disease and mainly focus on quality of life, whereas the medical professionals mainly look at diagnosis and treatment possibilities [15]. There are many reasons to increase the patients perspective in the health research cycle: legitimacy (democratic approach), contribution of experiental knowledge, increased likelyhood of implementation in practice and, most importantly, better quality of the decision making and more commitment for the results [16]. In this study the following definition of patient involvement is used: [13].

"The intention of patients and their organisation(s) contributing experiental knowledge is to exert more influence on patient issues, for example in health research. It is expected that usage of patients experience improves the relevance, quality and outcome of research. The level of patients' involvement may range from test subject via information provider or advisor to equal partner in re-

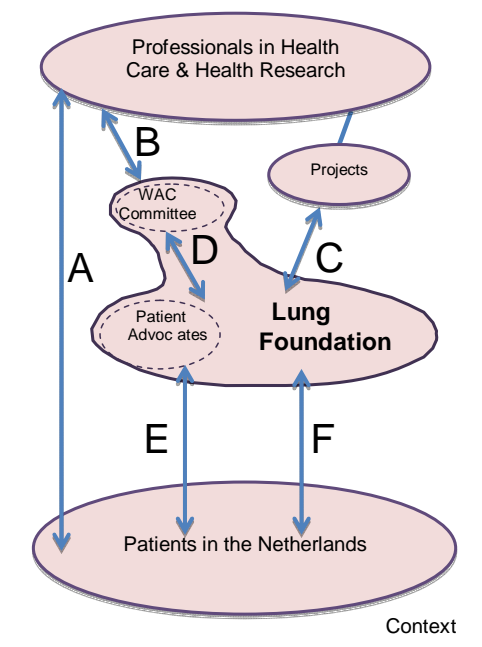

Figure 1. LFN patient involvement actors and interactions model (Explanation see chapter 3.2). search or quality of care."

This is based on the notion that patients know better about their interests, needs and issues than the other parties in the health system. Their collective experience constitutes a unique and specific perspective. So, patient involvement is about shared interests within the entire patient group and not about individual patient-care provider contacts.

\subsection{Setting, Actors and Interactions}

This study investigates the development process of patient involvement in LFN during a seven year period from 2005 till 2012. The LFN organisation is positioned between health care and health research professionals and lung disease patients in the Netherlands. The LFN organisation participates in mixed project teams among scientific institutions, care providers, insurance companies, government, industry and patient organisation representatives. In this study a simplified actors-interactions model of lung disease related health research activities is used with a societal "context" that surrounds the following actors: (see: Figure 1)

\subsubsection{Lung Foundation (LFN)}

The LFN organisation consists of two main parts: the LFN Lungfoundation and the LFN lung patients organisation. The LFN organisation funds scientific research for over 50 years, primarily on asthma and COPD but in recent years also on rare lung diseseases.

The WAC advises the LFN board on quality and priority of research proposals. At present both scientific quality and scientific and societal relevance are being actively considered.

\subsubsection{Scientific Advisory Committee LFN (WAC)}

Choosing health research funding themes on the "scientific research agenda" has mainly been the responsability of the members of the WAC for a number of years. The WAC members are professionals in the biomedical, clinical and health care research fields, contributing on basis of their personal expertise. From 2005 patient representatives are present in the WAC too.

\subsubsection{Health Research and Health Care Professionals}

The medical research professionals at universities, health institutes, care providers and expert centres submit project proposals after an LFN funding research call for fundamental, clinical and applied research proposals on subjects related to lung diseseases and living with a lung disease.

\subsubsection{Project Teams}

Mixed professionals project teams are used in various 
settings in the Netherlands and Europe to carry out research.

\subsubsection{Patient Advocates}

Some 20 to 25 patients with a lung disease, capable of forwarding experiental knowledge, inside and outside the LFN organisation, both in the Netherlands and on an international level, are organised in a "patient advocates" group. They contribute with patients involvement activities to the research cycle. They have provided patient issues for the societal research agenda in 2005 and for its update in 2009. In the WAC at first 1, later 3 patients were involved in decision making about research proposal funding.

\subsubsection{The (Lung Disease) Patient Group}

The group of 1 million patients with a lung disease in the Netherlands is the source of information for the LFN patient advocates. It is also a main target group, both for the LFN organisation and for the research professionals.

These actors have the following interactions: (see: Figure 1).

1) The Health research and health care professionals groups interact with patients in the Netherlands during care and research activities.

2) The LFN organisation interacts with health research professionals via the WAC. This deals with appraisal of research proposals, policy discussions, planning the health research agenda and patients involvement issues.

3) The LFN organisation interacts with project teams on health care and health research, both in the Netherlands and abroad. This is being done by LFN professionals and patient advocates and takes place outside the research funding process.

4) The "WAC" and "Patient Advocates" are part of the LFN organisation which has several interacting internal organs. WAC evaluates and prioritizes scientific research study proposals. The "Patients advocates" transform their experiental knowledge into different products: advocacy statements, processing forms, patient criteria, systematic appraisal of research calls and input to advice by the WAC.

5) The Patients advocates have a range of activities. Besides the product oriented activities they interact with lung patients in the Netherlands to gather experiental knowledge and "sense" the issues that matter among patients. They also defend patients' needs and interests, both on national and on local level, using data from the annual patient(member) monitoring and other monitoring instruments about chronic lung patients done by external parties.

6) The LFN organisation provides disease related information to lung patients in the Netherlands via pub- licity, provides support via an information service desk, and has local presence via 22 regional support workers. LFN also raises funds from the general public and receives minor contributions from industry and the government.

\subsection{The LFN Research Cycle and Patients' Perspective Anno 2012}

Patients' perspective is considered to be a crucial element in the entire research cycle according to the management, executive board and member council. Patients donate their experiential knowledge, their time, and their, due to their chronic lung disease, sometimes very limited energy to health research, quality of health care and quality of life. Patients take part in ethics committees, in research and care project groups and in development teams for health care guidance.

The LFN organisation manages the research cycle as a process having several stages. Both scientific and societal aspects are reviewed in a series of stages. The stages and the role of involved patients' are:

1) Establishing the research agenda. Using interviews and focusgroups the patient group is consulted about issues that matter and about subjects for future research.

2) Reviewing research proposals. Representatives from the patients advocates group evaluate submitted proposals on societal relevance from a patients' perspective in small groups of three patient advocates. LFN uses a standard review procedure with 5 criteria from patients’ perspective.

3) Prioritizing proposals based on the scores on the 5 criteria. This is carried out within the WAC by patient advocates sharing their experiental knowledge with the other (scientist) members. A general WAC meeting is being convened to review the results and compose the acceptability and priority advice listing to the LFN management.

4) After funding approval, stage four contains the start and execution of the research projects. Patients' involvement is not arranged via the LFN organisation in this stage.

5) Monitoring progress and scientific quality of research projects during execution and finalization is evaluated by the LFN research staff and the WAC as well. Evaluation from scientific and societal perspective is prepared by WAC members and LFN research staff. Patient involvement is not present in this stage.

\subsection{Context and Expected Changes}

In the field of lung disease related research and care activities in Western societies several changes were being observed during this study. In Europe and North America research proposals are no longer only appraised 
on their scientific quality and relevance. In the UK patients are involved in health care issues via the NHSInvolve for over a decade [17]. Emancipatory and democratic developments within groups of people with disabilities brings a new party to the health system negotiating table [1]. In stead of just looking at a disease from a medical point of view, the whole patient is currently at the focal point. These issues are especially felt by the growing group of patients with a chronic disease, and get more important in all aspects of their lives than before. Rather than just one, three phases are now to be dealt with in the health system:

1) Contracting a disease-requiring treatment, facility and quality of care;

2) Keeping the disease-requiring self-management and quality of care;

3) Learning to live with the disease-requiring social participation and quality of care.

Chronic patients build up experiental knowledge over the years, a new type of knowledge, represented by a new party during negotiations in health research and health care. Being new at this however, patients face practical problems affecting their efficient and effective contribution. Their disease makes it in many cases difficult to always attend at meetings. There was no consistency in the quality of their contribution and there was no instrument for appraisal of proposals from patients perspective [16].

Patient needs shift towards quality of life related societal issues, leading to a shift in the research agenda [18]. Governments have started to support patients taking control over their own lives by self-management and a stronger advocacy role in the health care system policy, health cost and health insurance debate [19].

Increased individuality and autonomy of people in general also affects (chronic) patients. A newly acquired chronic disease is a dramatic change and it is a daunting task to create a new, equally individual, way of life. The importance of self-management is expected to increase due to increasing numbers of chronic disease patients [20]. The traditional medical approach via diagnosis and therapy needs to be extended to a partnership between a well informed patient and a care provider.

Governments stimulate patient organisations to participate in the development of guidance and research agenda setting [17].

Respondent researchers and care providers did not regard patients as experts since all relevant knowledge is assumed to reside with professionals. Patient groups on the other hand were very positive about being involved. In their view increasingly important chronic illnesses and the trend from "only cure" to "also care" would lead to a new setting: medical professionals "coaching” the patients in deciding and managing quality of life issues via “selfmanagement”. Patient respondents also recognize a danger: patient involvement could be abused to achieve the goals of the other parties, leading to pseudo-involvement or "placation".

In spite of countries having different health systems, different legislation regarding health insurance and different ways patients are organised as a collective, issues that matter to patients remain uniform [15]. Efficient and effective involvement via patient advocates is troubled by poor contact with patients in the groups represented. In various countries patients are involved on personal capacity only. In order to be able to gather up to date information in a patient group, the advocates need to be adequately equipped. Due to usage of complicated professional language patient advocates need a large amount of time to evaluate reports and documents [21]. Patient advocates in chronical illness patient groups also face continuity problems. Their illness often causes difficultties with attending meetings. Patient advocates face power differences, poorly operationalised criteria and otherwise unclear definition of their involvement [17, 22-25].

\subsection{Interventions}

During this case study there was one single major intervention: the introduction of patient involvement in the LFN cycle of research funding.

\section{RESULTS}

In order to allow comparison and analysis a data collection theme list according to Table $\mathbf{1}$ was used. This list has seven aspects and was derived from critical analysis of the patient involvement as it was at LFN before 2005 [26]. Based upon 5 key changes in policy and practic at LFN 5 time crossectional descriptions were made according to Table 2 .

Then, using the situation descriptions gathered from documents, interviews and focus group observations, the development histories for each of the seven aspects were described including a critical reflection by each of the seven aspects.

\subsection{Research Basis}

The scientific research agenda is initiated and composed by scientific and health care professionals in 1999 . It is still in use in 2005. In 2004 a scientific study on a societal agenda was started.

As a first change towards patient involvement in the LFN research cycle in 2006 a societal research agenda was composed in cooperation between researchers, health care professionals, patients and other relevant stakeholders for the first time. In 2010, 2011 and 2012 the basis is an updated Societal research agenda, jointly 
Table 1. Template for the LFN research cycle patient involvement case study.

\begin{tabular}{|c|c|c|}
\hline $\mathrm{Nr}$ & Aspect & Description \\
\hline 1 & $\begin{array}{l}\text { Research } \\
\text { basis }\end{array}$ & $\begin{array}{l}\text { What basis initiates and chooses themes } \\
\text { for scientific research }\end{array}$ \\
\hline 2 & $\begin{array}{l}\text { Funding } \\
\text { criteria }\end{array}$ & $\begin{array}{l}\text { What appraisal criteria are leading in } \\
\text { LFN research }\end{array}$ \\
\hline 3 & Patients say & $\begin{array}{c}\text { What is the basis for LFN patients' say in } \\
\text { research }\end{array}$ \\
\hline 4 & Scope & $\begin{array}{c}\text { What is the scope of LFN appraisal of } \\
\text { patients' involvement }\end{array}$ \\
\hline 5 & Advocacy & $\begin{array}{c}\text { How is LFN patient advocacy in research } \\
\text { organised }\end{array}$ \\
\hline 6 & Commitment & $\begin{array}{c}\text { What is the level of commitment for LFN } \\
\text { patient involvement }\end{array}$ \\
\hline 7 & Context & $\begin{array}{l}\text { What contextual and paradigm } \\
\text { considerations play a role }\end{array}$ \\
\hline
\end{tabular}

Table 2. Situation descriptions at 5 discrete moments during the study period.

\begin{tabular}{ccc}
\hline Phase & Time cross section & Description \\
\hline I & Research cycles & Introduction societal research \\
& up to 2005 & agenda, vision and system \\
II & $2005-2009$ & Update societal agenda \\
& research cycles & \\
III & 2010 & Patient expert group \\
& research cycle & \\
IV & 2011 & Societal relevance criteria \\
& research cycle & \\
V & situation planning & Present situation \\
\hline
\end{tabular}

prepared with researchers, care professionals, lung patients and other relevant stakeholders [27].

\section{Critical Reflection}

At the start of the case study period generally, scientists were suspicious about the added value of patient involvement for a long time. Some of them even considered appraisal by patients as a threat to their position in the research field. Traditionally researchers and professionals minimise the influence by third parties on the contents of their work [28]. Researchers often want to protect their power/status and promote the authenticity and supremacy of their knowledge over consumer- or patient lay knowledge [29]. Patient involvement brings "different" perspectives to research decision-making spaces, based on what has been referred to as "experiential expertise [30]. The separation of scientific quality and relevance from societal relevance as introduced by LFN was therefore crucial. Separated appraisal allowed the point of view to change and mutually acknowledge the potential added value of each others" appraisal. Currently research scientists still not all whole- heartedly commit to it. Since it requires a "culture" change this takes some more time and effort.

It is also crucial for researchers to be aware of other distinctive patient voices rather than the "average" as that is mostly based upon dominant methodological or policy assumptions. Both in general and in this study it is a concern how the vulnerable group within the total patient group can be heard. Diverse patients will express diverse opinions and the patient perspective can become more than an averaged out "mainstream-mix" that can simply be compared to a standard [31].

\subsection{Funding Criteria}

Upto 2009 scientific quality was the leading primary criterion in the research funding process. Scientific and societal relevance were handled as a single secondary criterion. From 2010 scientific and societal relevance were handled as two separate criteria, remaining of secondary importance. This split-up of "relevance" was an important change. In the 2010 LFN research cycle, the patients' perspective was introduced as a new conditional requirement into the call for proposals. If not properly addressed these additional patient criteria would lead to exclusion from the funding cycle. In 2011 the LFN funding application and appraisal procedure was changed to accomodate patient involvement requirements and to clarify patient criteria to the research community. By 2012 scientific and societal parts had equal weights.

\section{Critical Reflection}

In theory, societal and scientific relevance criteria are equally important and must be allocated equal weight in health research. In practice however, scientific quality reigns. It is decisive for a project proposal to pass through the first phase, whatever its societal relevance. The question is whether this does justice to all parties involved, especially the patients. Recently, in both the scientific and the societal policy discourse, besides relevance, also working with societal quality equal to scientific quality has become more accepted. The social quality of research, also called valorisation, means making a result of research valuable for society. This more comprehensive research evaluation, including questions about "societal quality" and "valorisation", requires a broad discussion and an approach with a wide participation of disciplines and other stakeholders [32]. Patients are much in favour of the addition of societal relevance as an appraisal criterion but this has no bearing on the commitment for this with other stakeholders in the LFN process. The decision making process in the WAC about the advice to reject or approve and prioritize proposals is carried out by ranking on individual votes against a total funding budget constraint. This means that rejection does 
not imply the proposal is substandard in all cases.

\subsection{Patients Involvement and Patient Perspective}

From the year 1998 patients were consulted by LFN. In 2004 a Patient Advisory Group was used to assess issues that matter to patients. Patients provided advice when asked and when patients felt advice was necessary and appropriate on a wide range of subjects [26]. Before 2005 LFN strategy and policy documents did not mention patient involvement. A study on societal agenda setting was published in 2005 [18]. Patient involvement was implicitly mentioned in LFN research policy by 2009. Patient involvement was explicitly mentioned in LFN research policy by 2011. Patient involvement is explicitly mentioned both in the LFN strategic plan and in the LFN research policy in 2012.

\section{Critical Reflection}

Working with budget allocation and dedicated support for patient involvement activities still is in its infancy. Althoug a specialist policy advisor has been working on this for 3 years and a group of patient advocacy volunteers was built 2 years ago, involvement is stil far from being structural and sustainable.

\subsection{Scope}

In 2005 there was only 1 tick-box: "is patient involvement sufficiently being addressed?" on the funding application form. By 2010 a detailed description of how patient perspective is implemented in the proposed research project was required. The Societal relevance requirement contained "patient criteria". Working with patient criteria was a key change in the process $[15,16]$. Patients in health care, the test subjects in health research and the research professionals had identified the need for a set of appraisal criteria. In 2011 societal relevance was extended to 5 criteria: "relevance", "quality of life", "quality of care", "information/communication" and "right to say". A requirement on a lay-summary description with research questions, workplan and schedule, in Dutch was introduced, to assist the appraisal by patient advocates.

\section{Critical Reflection}

Using 5 patient criteria turned out to be very helpful for the patient advocates. Unfortunately the lay-summary in the local and "plain" language still often misses in proposal packages to be appraised. Researchers appear to favour writing in English. Both the right depth in the description of the project contents in the lay-summary, and its readability in the local language, require further attention. It is this lay-summary that avoids social ex- clusion and enables patient advocates to adequately fulfill their role.

\subsection{Advocacy}

Chronic lung patients did not have a group of patient advocates capable of defending their interests on a national and international level before 2005. In 2005 the WAC effectively had one patient member. Between 2005 and 2009 two lung patients participated in the WAC, based on their personal capacity. These two became also member of a newly established group of lung patients with experiental knowledge. This was a key change in the process. The group was advocating on (inter)national level, and was being facilitated by an LFN staff professional from 2010. In 2010 the two patient WAC members had difficulties to consult with the chronic lung patients in the country and getting some more support. The group of lung patients with experiental knowledge, then engaged in appraisal of 71 research proposals, using 3 "patient criteria". This was done in small appraisal teams of minimum 3 expert patients for continuity reasons. Participants were compensated for travel expenses. By 2011 three lung patients participated in the WAC as equal partners. The patient advocates group handled the appraisal of 90 research proposals, on societal relevance using a 5 "patient criteria" list as a tool. Two additional weeks throughput time were allocated to the review process for appraisal of the societal elements in the large quantity of research proposals.

\section{Critical Reflection}

The 3 patient WAC members are still a minority (20\%) when it comes to voting on rejection or acceptance. Also the 2 weeks throughput time they originally had for proposal appraisal was rather short. Many of the patient representatives have a job, a household or simply themselves and their disease to manage and have limited capacity to do advocacy work on the side. This was not in line with LFN organisation research application procedures, geared to professionals that appraise project proposals as a part of their day-jobs.

\subsection{Commitment}

Patient involvement was not considered to be an important factor before 2005. Commitment for patient involvement was poor with professionals, both inside and outside the LFN up to 2009. Although LFN policy mentioned patient involvement, practice showed very little evidence. The patient involvement in the research cycle was further intensified every year based on experience and discussions with the patient members in the WAC. There was a fair to adequate level of commitment by 2010. By 2011 commitment was good considering the 
policy and its implementation in practice. By 2012 patient involvement was widely accepted in the LFN organisation and it was mentioned in the LFN strategy, in the research policy and in the annual budget allocation for training and information exchange. It was implemented in practice via facilitation of the patient advocates group.

\section{Critical Reflection}

The commitment of LFN organization, WAC members and researchers in the funding cycle has increased during the 7 years of this case study. Continuity strongly depends of highly motivated professionals in the WAC, specialy the chairmen, and in the LFN organization, so-called "believers" however. The appointment of a new chairperson of the WAC in 2012 will also be crucial.

\subsection{Context}

In 2005 patient involvement, equal partnership, full citizenship and own responsibility were emerging phenomena in society. They were being discussed between government, health insurance and health providers as potential subjects for new policy. Between 2005 and 2009 government institution ZonMw started a research programme on patient involvement in health research and quality of care in order to speed up patient involvement and make it more efficient and effective. The LFN organisation was the first health fund to set up a societal research agenda. In 2012 government budget cuts caused the withdrawal of part of the financial support for advocacy to patient organisations. Emphasis was placed on patient organisations' own responsibility and cooperation with each other.

\section{Critical Reflection}

Government programme funding ends in 2013. Budget cuts, elections in the Netherlands and European Union economic problems make further "patient involvement development” funding unlikely [31,33].

\section{ANALYSIS}

The effect of the intervention on the quality, efficiency and effectiveness of patient involvement was derived from observations, interviews and focusgroup findings. An important change was the introduction of a lay language summary in Dutch. An observation during the many appraisals was that proposals that had such summaries, were often also addressing readability of information for test subjects in their project. Although much improvement was observed, research proposals often still lack information about the expected results on short or long term and the impact on the quality of life for the patient group. Equal partnerships include involvement in all research activities from beginning to end. But also a focus on experiential knowledge, mutual learning, openness, and respect are needed. The idea of a mutual learning process helps to close the gap between ideas of "real value" professional knowledge and "lesser worth" lay knowledge, it might even overcome these stereotypes. The collaboration can have an extra value for the research process and for those involved [34]. It may be useful in the nearby future to differentiate the value of participation by the levels of the individual patient, the patient group, the patient association, the researchers and the Health Fund platform [35]. Finally, there might be a beneficial insight for the research community in the Netherlands and abroad. Patient criteria on societal relevance were not seen before in the health research area so explicitly stated as in this case study. A rise in quality level of proposals and implementation of results may be expected since now all parties involved (careand research professionals and patients) contribute their expert knowledge.

\section{DISCUSSION}

This study is about getting lung patients involved in the LFN health research funding process. Arguably the observed shift in vision and commitment for patient involvement may depend partly on general societal and political trends and a change of thinking among the general population over time. On the other hand one can say that if LFN had not consciously chosen for an intervention-to implement patient involvement in the research cycle-this would not have translated into a new and better balanced approach in health research funding. Quality improvement was achieved since all parties are now being involved. A critical success factor is well motivated expert patients group. At the same time it is also the main risk factor for the process. A sufficient number of qualified patients, available and able to carry out the work needed for effective patient involvement, is crucial. Patient advocates at LFN do this as a volunteer, often on the side of other activities. The financial support for patient involvement activities is easily prioritized when budget cuts are needed, making it vulnerable.

\subsection{Limitations to This Study}

There is allways the question whether the analysis of qualitative data is sound and meaningful [7]. To this end we gathered, described and analysed in a completely transparent way. The research cycle, subject to intervention in this study, exists not only in the LFN organisation but in many similar patient organisations and fund raising organisations in many countries. Findings might be influenced by changes on different contextual 
levels [8]. On the one hand the perspective of neither the researcher, nor the LFN organisations' main strategy have changed during this study. As a consequence of the intervention the patient involvement related activities became more structured, more explicit as societal relevance and embedded as a requirement, hence more important. The socio-economic context on the other hand has changed considerably. After three research cycles in the new situation it is highly likely that true effects are observed, not affected by a wrongly chosen start or stop moment in time or duration of observation. The immediate future may be affected by the reduction or even withdrawal of goverment activities in this field. This may require new ways and new conditions for cooperation with industry. The effects of the new LFN research funding cycle review procedure require further monitoring to see if patterns evolve in the subjects addressed in proposals approved versus proposals rejected. This monitoring step was not yet implemented at the time the case study was ended in 2012.

\subsection{Recommendations}

This study shows that creating commitment among all stakeholders took quite a while. Although expectations are favourable, proving the added value of patient involvement in the research cycle is an important subject for further study. As a result patient organisations will gain specific expertise in acting as a partner in research, and researchers will involve patient representatives or advocates in more or even all aspects of their research. From a patients' point of view it is difficult to accept that it may happen that a typical "patient research subject" is not approved for funding by LFN. Further pursuit of funding may require new liaisons and cooperation outside the own patient organisation, either on national level or on international level, e.g. in the European Commission environment. Doing this appraisal process properly requires "believers": highly motivated and capable expert patients and dedicated staff for support, as well as researchers. This crucial contribution also identifies a weakness: what happens if they leave? In this case study a practical solution was mentioned: a group of 25 expert patients, working in small teams (3 or more members) dividing the work in many small portions. If one of the small team members cannot make it to a meeting the other team members can still complete the task at hand. The experiences during the period 2007-2012 at LFN have attracted the attention of other patient organisations and health funding organisations. Some are working now on an adapted form for their own use [36,37]. More cooperation between disease specific patient organisations on general aspects like fatigue, work, education access will strengthen the voice of the patient in health research. Research projects should en- sure the allocation of a budget to patient involvement. Foundations and government should take up patient involvement in their policies and practice. The knowledge associated with the practice of patient involvement needs to be managed and made accessible.

\section{CONCLUSION}

Based on this seven years case study we conclude that patients' involvement in health research is practicable, both in applied research and in fundamental/clinical research. The LFN review procedure was changed and all stakeholders are now participating in its execution. It proved to be workable for patient representatives, provided they can make use of an appraisal criteria instrument. Also they need support by professionals for their training, and for creating and keeping together a peergroup of expert patients. Patient involvement at LFN has become more effective and more efficient. Still patient involvement can be further improved, in process and outcome but also in representing the "silent voice" among the patients. Patient involvement remains dependent on individuals and "believers". Commitment is not yet supported by hard evidence of effectiveness. The vulnerability of individuals in the peer-group of expert patients requires-besides compassion-also management of experiental knowledge and its continuity. It is not realistic to assume that the voices of all kinds of patients are equally well heard, the way patient involvement is currently organized. It is a serious point of concern that the the "silent voices" of vulnerable patients are not likely to be heard among the patients representatives, although they deserve to be heard in the research process. This seven year study offers valuable insight in patient involvement against the background of the changeing health discourse. It is an example with successes, failures and pitfalls during the introduction and implementation of patient involvement in lungdisease related health research. There are do's and dont's which can be useful for other patient organisations and fund raising organisations in other countries. Commitment for patient involvement, well equipped patient advocates and systematic gathering of up to date patient group information, are key conditions for structural and sustainable patient involvement. Besides this an allocated budget, suitable tools for proposal evaluation and agreed funding application procedure details about patient involvement and criteria, are necessities in the process. Funding of lung disease related health research may now be more directed towards issues relevant to chronic lung patients than before. Both patient advocates and health research professionals will need to adapt to this shifting balance.

\section{ACKNOWLEDGEMENTS}

This case study was made possible thanks to the cooperation be- 
tween the Lungfoundation (LFN) in Amersfoort and the VU University Medical Center, EMGO+, Dept. Medical Humanities in Amsterdam. The authors of both institutions thank all those involved in the 7 years period for their continued support to the worthy cause of developing patient involvement in health research.

\section{REFERENCES}

[1] WHO (2011) World report on disability, WHO/NMH/ 11.01, Geneva.

[2] Astma Fonds (2012) Handleiding vooraanmeling onderzoek. Astmafonds 2012.

[3] Yin, R.K., Green, J.L., Camilli, G. and Elmore, P.B. (2006) Handbook of complementary methods in education research. Lawrence Erlbaum Associates Publishers, Mahwah, xxix, 863 Pages.

[4] Yin, R.K. (1994) Case study research: Design and methods. Thousand Oaks.

[5] Eisenhardt, K.M. (1991) Better stories and better constructs: The case for rigor and comparative logic. Academy of Management Review, 16, 620-627.

[6] Eisenhardt, K.M. (1989) Building theories from case study research. The Academy of Management Review, 14, 532-550.

[7] Kohn, L.T. (1997) Methods in case study analysis. The Center for Studying Health System Change. Technical Publication No. 2, June 1997 (Based on Panel Discussion Conducted at the 1996 Meeting of the Association for Health Services Research).

[8] Pettigrew, A.M. (1990) Longitudinal field research on change: Theory and practice. Organization Science, 1, 267292. doi:10.1287/orsc.1.3.267

[9] Stein, T., Frankel, R.M. and Krupat, E. (2005) Enhancing clinician communication skills in a large healthcare organization: A longitudinal case study. Patient Education and Counseling, 58, 4-12. doi:10.1016/j.pec.2005.01.014

[10] Bowen, G.A. (2006) Grounded theory and sensitizing concepts. International Journal of Qualitative Methods, 5 Article 2.

[11] WMA-World Medical Association (2008) Declaration of helsinki. Seoul.

[12] Devers, K.J. (1999) How will we know "good" qualitative research when we see it? Beginning the dialogue in health services research. Health Services Research, 34, 1153-1188.

[13] van Bijsterveldt, M. and Dekker, E. (2006) Handboek patiëntenparticipatie in wetenschappelijk onderzoek. ZONMw. www.zonmw.nl/patiëntenperspectief

[14] Ursum, J., Rijken, M., Heijmans, M., Cardol, M. and Schellevis, F. (2011) Zorg voor chronische zieken, organisatie van zorg, zelfmanagement, zelfredzaamheid en participatie. Nivel, Utrecht. http://www.nivel.nl/nieuws/overzichtstudie-zorg-voor-chr onisch-zieken-een-nieuwe-rol-voor-zorgverleners

[15] Teunissen, G.J., Visse, M.A., de Boer, W.I. and Abma,
T.A. (2011) Patient issues in health research and quality of care: An inventory and data synthesis. Health EXpectations. doi:10.1111/j.1369-7625.2011.00718.x

[16] Teunissen, G.J. and Abma, T.A. (2010) Derde partij tussen droom en daad. Tijdschrift voor Sociale Gezondheidszorg, 182-189.

[17] (2009) Involve 2009. P1: Getting involved in research grant applications, Guidelines for members of the public, NHS - National Institute for Health Research, and P2: Peer reviewing research proposals, Guidelines for members of the public. DH Department of Health. http://www.invo.org.uk

[18] Caron-Flinterman, J.F. (2005) A new voice in science: Patient participation in decision making on biomedical research. Thesis, VU-Free University, Amsterdam.

[19] Keizer B (2012) Exchanging knowledge on participation of health consumers and patients in research, quality and policy. April 2012, ZONMw: Den Haag

[20] Heijmans, M., Spreeuwenberg, P. and Rijken, M. (2010) Ontwikkelingen in de zorg voor chronisch zieken, rapportage 2010. NIVEL, Utrecht.

[21] Trappenburg, M.J. and van de Bovenkamp, H. (2008) Patient involvement in guideline development reconsidered. Health Care Analysis, 17, 198-216.

[22] Nierse, C. and Abma, T.A. (2011) Developing voice and empowerment: the first step towards a broad consultation in research agenda setting. Journal of Intellectual Disability Research, 55, 411-421. doi:10.1111/j.1365-2788.2011.01388.x

[23] Visse, M.A., Teunissen, T., Peters, A., Widdershoven, G. and Abma, T.A. (2010) Dialogue for air, air for dialogue. Toward shared responsibilities in COPD practice. Health Care Analysis, 18, 358-373. doi:10.1007/s10728-009-0139-7

[24] Abma, T.A. and Broerse, J.E.W. (2010) Patient participation as dialogue: Setting research agendas. Health Expectations, 13, 160-173. doi:10.1111/j.1369-7625.2009.00549.x

[25] Williamson, C. (2010) Towards the emancipation of patients: Patients' experiences and the patient: Patients experiences and the patient movement. The Policy Press, University of Bristol, Bristol, 2010. Hobbs Southampton.

[26] Caron-Flinterman, J.F., Broerse, J.E.W., Teerling, J. and Bunders, J.F.G. (2005) Patients' priorities concerning health research: The case of asthma and COPD research in the Netherlands. Health Expectations, 8, 253-263. doi:10.1111/j.1369-7625.2005.00337.x

[27] Elberse J, Laan D, de Cock Buning T, Teunissen T, Broerse, J. and de Boer, W. (2012) Patient involvement in agenda setting for respiratory research in the Netherlands. European Respiratory Journal, 40, 508-510. doi:10.1183/09031936.00018812

[28] Bovenkamp, H., Grit, K. and Bal, R. (2008) Inventarisatie patiëntenparticipatie in onderzoek, kwaliteit en beleid. Rotterdam: iBMG/EUR Erasmus MC.

[29] Boote, J. (2009) Critical perspectives on 'consumer involvement' in health research: Epistemological dissonance and the know-do gap. Journal of Sociology. 
[30] Thompson, J., Bissell, P., Cooper, C., Armitage, C.J. and Barber, R. (2012) Credibility and the 'professionalized' lay expert: Reflections on the dilemmas and opportunities of public involvement in health research. Health (London), 16, 602-608. doi:10.1177/1363459312441008

[31] Barnes, M. and Cotterell, P. (2012) Critical perspectives on user involvement. The Policy Press, University of Bristol, Bristol.

[32] Spaapen, J., Dijstelbloem, H. and Wamelink, F. (2007) Evaluating research in context, a method for comprehensive assessment. The Haque NOW.

[33] GR/RVZ Gezondheidsraad/Raad voor volksgezondheid en zorg (2012) Toekomstverkenning ethiek en gezondheid. Signalering Ethiek en Gezondheid. Centrum voor Ethiek en Gezondheid, Den Haag.
[34] Abma, T.A., Nierse, C.J. and Widdershoven, C.A.M. (2009) Patients as partners in responsive research: Methodological notions for collaborations in mixed research teams. Qualitative Health Research, 19, 401-415. doi:10.1177/1049732309331869

[35] Denis, A. and Teller, M. (2011) Hefbomen voor beter patienten particpatie Nieuwe praktijken en mogelijkheden voor erkenning en financiering. Boudewijn stichting, Brussel.

[36] U-Biopred, PRO active projects patient criteria list link. http://www.ubiopred.european-lung-foundation.org/1787 2-patient-perspective-in-research-booklet.htm

[37] PGO patient criteria list link. http://www.pgosupport.nl/mailings/FILES/plugin content 194/Criteria-waaier7.0.pdf 